Research Article

\title{
Comparative study of theophylline and doxofylline in the treatment of stable chronic obstructive pulmonary disease
}

\author{
${\text { Panduranga Rao } \text { Nagawaram }^{1} * \text {, Vashishta Kanchanpally }}^{2}$
}

\begin{abstract}
${ }^{1}$ Great Eastern Medical School and Hospital, Ragolu Village, Srikakulum, Andhra Pradesh 532484, India,

${ }^{2}$ Malla Reddy Medical College for Women, Suraram 'x' Road, Qutbullapur Municipality, Jeedimetla, Hyderabad, Telangana 500 055, India
\end{abstract}

Received: 23 January 2016 Accepted: 06 February 2016

*Correspondence to:

Dr. Panduranga Rao

Nagawaram,

Email: panduranga.nagawaram @gmail.com

Copyright: (c) the author(s), publisher and licensee Medip Academy. This is an openaccess article distributed under the terms of the Creative Commons Attribution NonCommercial License, which permits unrestricted noncommercial use, distribution, and reproduction in any medium, provided the original work is properly cited.

\begin{abstract}
Background: COPD is one of the major public health problems worldwide. Theophylline has been used in the treatment of COPD for decades. Doxofylline a new theophylline congener has been claimed to have better safety profile. The study was undertaken to compare theophylline and doxophylline at doses recommended and commonly used in clinical practice.

Methods: The study was conducted in patients of COPD in TB chest department of Osmania medical college hospital. It was an open label, randomized, prospective parallel group study of 12 weeks duration. A total of 40 patients were divided in two groups. Group I was administered $400 \mathrm{mg}$ theophylline sustained release tablets once daily orally and group II was administered doxofylline $400 \mathrm{mg}$ twice a day orally. Spirometric variables symptom score, and adverse effects were recorded on days 0 , week 1 , week 6 and 12 of therapy. Data were compared and statistical analysis was performed using the Prism Graphpad 6, USA.

Results: There was no statistically significant difference with respect to spirometric variables and symptom score in the two groups and no significant difference in two groups with respect to side effects $(\mathrm{p}>0.05)$.

Conclusions: Both doxofylline and theophylline significantly improved spirometric values and there was significant improvement in symptoms cough, shortness of breath and nocturnal severity of symptoms. There was a significant reduction in the use of at rescue medication during the treatment with both the drugs.
\end{abstract}

Keywords: COPD, Doxofylline, Theophylline, Spirometry

\section{INTRODUCTION}

Chronic obstructive pulmonary disease (COPD) is a common, preventable lung disorder characterized by progressive, poorly reversible airflow limitation often with systemic manifestations, in response to tobacco smoke and/or other harmful inhalational exposures. ${ }^{1}$

According to WHO, 65 million people have moderate to severe COPD and is estimated to be the $3^{\text {rd }}$ leading cause of death by $2030 .^{2}$ Crude estimates suggest that there are
30 million COPD patients in India. ${ }^{3}$ It is an often under diagnosed and life threatening disease and its incidence is on rise due to increased smoking, widespread use of biomass fuel and co-morbid infectious diseases. The disease presents with symptoms of cough, sputum production, or dyspnea (difficult or laboured breathing), and/or a history of exposure to risk factors for the disease and the diagnosis is confirmed by spirometry.

Management of chronic stable COPD aims to prevent exacerbations and improve lung function through drug 
and $\mathrm{O}_{2}$ therapy, smoking cessation, exercise, enhancement of nutrition, and pulmonary rehabilitation. Drug treatment includes bronchodilators and corticosteroids or both. Bronchodilators include inhaled beta-agonists and anticholinergics and methylxanthines. Theophylline is a competitive nonselective phosphodiesterase inhibitor, which raises intracellular cAMP, activates PKA, inhibits TNF-alpha and inhibits leukotriene synthesis and reduces inflammation. ${ }^{4-7}$ It is a nonselective adenosine receptor antagonist, antagonizing A1, A2, and A3 receptors almost equally, which explains many of its cardiac effects. ${ }^{8}$ Doxofylline is a xanthine bronchodilator which has greatly decreased affinity towards adenosine A1 and A2 receptors which explain its better safety profile and less cardiac side effects.

In this present study, the safety and efficacy of doxofylline in comparison with theophylline in the treatment of moderate COPD were reviewed.

\section{METHODS}

This study was conducted in the Department of Pharmacology and Department of TB and Respiratory Diseases, Osmania medical college, Hyderabad which was approved by institutional ethics committee and an informed consent was taken from all the patients before enrolling them in the study. This is an open label, randomized, prospective parallel group study of 12 weeks duration. The inclusion criteria were, male patients above the age of 18 years of age, who were diagnosed clinically and spirometrically with COPD, who had the complaints of breathlessness, cough with sputum, and with history of smoking. Patients with baseline spirometry of (FEV1) between $50-80 \%$ of the predicted value were included in the study. The exclusion criteria includes complicated cases of chronic obstructive pulmonary disease with respiratory failure, patients with clinically significant lung disease other than COPD, patients with a history of hepatic, renal, cardiovascular and neurologic diseases which require treatment, pregnant and lactating mothers, Subjects who quit smoking less than 3 months prior to the screening visit and those already on methyxanthines. A case record form, adverse drug reaction form were devised to capture all the data during the study. Demographic data was collected from all the patients. Detailed medical history with general and systemic examination was done. All the baseline investigations were done. The patients were randomly allocated into two groups and given study numbers. Group I patients were administered Theophylline, sustained release 400 mg once daily and group II patients were administered doxofylline $400 \mathrm{mg}$ twice daily, orally for a duration of 12 weeks. All patients are advised to take rescue salbutamol inhalation $100-150 \mathrm{mg}$ if the symptoms are not controlled with the prescribed medication.

\section{Efficacy assessment}

The efficacy of doxofylline was compared with theophylline on the basis of the clinical improvement of the symptom scores and the spirometric parameters before and after the drug treatment. The symptom score included shortness of breath, cough, night symptomatic symptoms and frequency of use of rescue medication.

FEV1, FVC and the ratio of FEV1 and FVC were recorded on days 0 , week 1 , week 6 and 12 of [in the actual study: P.F.T:-FEVI, FVC, $\mathrm{FEV}_{1} / \mathrm{FVC}^{2}$. Baseline on $1^{\text {st }}$ day, $3^{\text {rd }}$ day, $7^{\text {th }}$ day thereafter every $2^{\text {nd }}$ week for a period of 12 weeks the drug treatment. The pulmonary function tests were done by using SPIROLAB II (MIR).

\section{Safety assessment}

The adverse events reported by the patients or observed by the investigator were recorded at each visit. Renal and hepatic parameters were assessed before and after completion of study.

\section{Statistical analysis}

Data are expressed as Mean \pm SD. Paired t- test and unpaired t-test were performed for within group and between groups analysis respectively. A p-value $<0.05$ was considered to be statistically significant. All statistical analysis was performed using the Prism Graphpad 6, USA.

\section{RESULTS}

A total of 50 patients were screened and 40 eligible patients were randomized and included in the study. Twenty patients were randomized to each group, among which 2 patients in theophylline group dropped out of the study. The mean age of the patients in doxofylline group was $55.7 \pm 1.02$ and mean age of patients in theophylline group was $55.45 \pm 0.745$.

There were no significant differences between treatment groups in baseline characteristics including age, weight and body mass index indicating a homogenous population.

In the spirometric assessment values showed significant improvement in FEV1 with respective baseline at the end of 12 weeks in both the groups of patients. The mean FEV1 improved by 0.62 liters $(45 \%)$ in theophylline group and by 0.561 liters $(40.2 \%)$ in doxofylline group at the end of treatment $(\mathrm{P}<0.01)$. At the end point mean FVC value improved by 0.449 liters $(21.87 \%)$ in theophylline group and by 0.425 liters $(17.9 \%)$ in doxofylline group, in comparison with baseline values $(\mathrm{P}<0.01)$. The mean FEV1/FVC\% ratio also improved by $19.69 \%$ in theophylline group and by $25.32 \%$ in doxofylline group, compared with baseline $(\mathrm{P}<0.01)$ (Table 1, Figures 1-4). 
Table 1: Spirometric changes in mean values of FEV1, FVC and FEV1/FVC before and after the therapy.

\begin{tabular}{|c|c|c|c|c|c|c|c|c|c|}
\hline \multirow[t]{2}{*}{ Group } & \multicolumn{3}{|l|}{$\mathrm{FEV}_{1}$} & \multicolumn{3}{|l|}{ FVC } & \multicolumn{3}{|c|}{ FEV1 / FVC\% } \\
\hline & $\begin{array}{l}\text { Mean } \\
\text { value } \\
\text { before Rx }\end{array}$ & $\begin{array}{l}\text { Mean } \\
\text { value } \\
\text { after Rx }\end{array}$ & $\begin{array}{l}\text { Mean } \\
\text { change } \\
\%\end{array}$ & $\begin{array}{l}\text { Mean } \\
\text { value } \\
\text { before Rx }\end{array}$ & $\begin{array}{l}\text { Mean } \\
\text { value } \\
\text { after Rx }\end{array}$ & $\begin{array}{l}\text { Mean } \\
\text { change } \\
\%\end{array}$ & $\begin{array}{l}\text { Mean } \\
\text { value } \\
\text { before Rx }\end{array}$ & $\begin{array}{l}\text { Mean } \\
\text { value } \\
\text { after Rx }\end{array}$ & $\begin{array}{l}\text { Mean } \\
\text { change } \\
\%\end{array}$ \\
\hline $\begin{array}{l}\text { I Theophylline } \\
\mathrm{N}=18\end{array}$ & 1.35 & 1.97 & 45.92 & 2.057 & 2.506 & 21.87 & 65.65 & 78.58 & 19.69 \\
\hline $\begin{array}{l}\text { II Doxofylline } \\
\mathrm{N}=20\end{array}$ & 1.393 & 1.954 & 40.2 & 2.376 & 2.801 & 17.9 & 58.514 & 73.33 & 25.32 \\
\hline
\end{tabular}

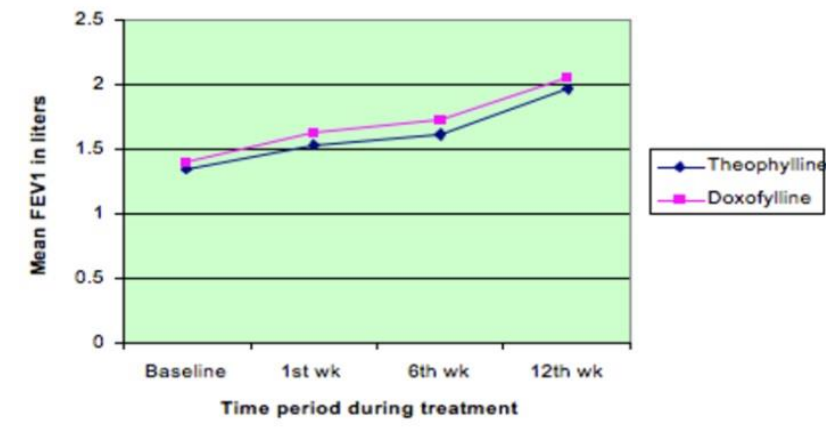

Figure 1: Spirometric changes in mean values of FEV1 during the therapy with doxofylline and theophylline.

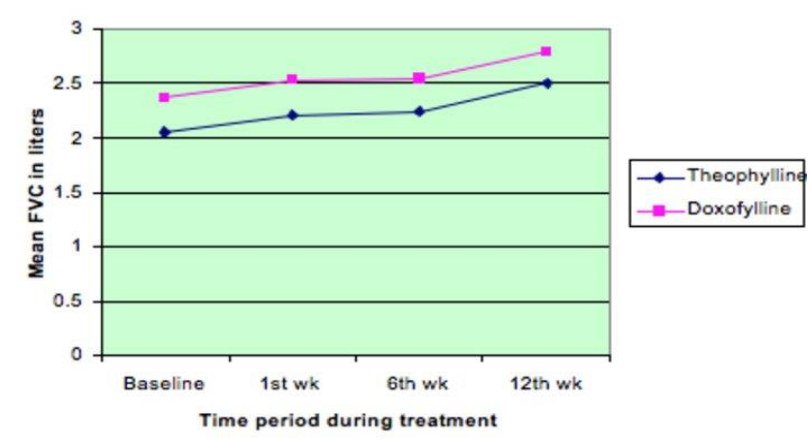

Figure 2: Spirometric changes in mean values of FVC during the therapy with doxofylline and theophylline.

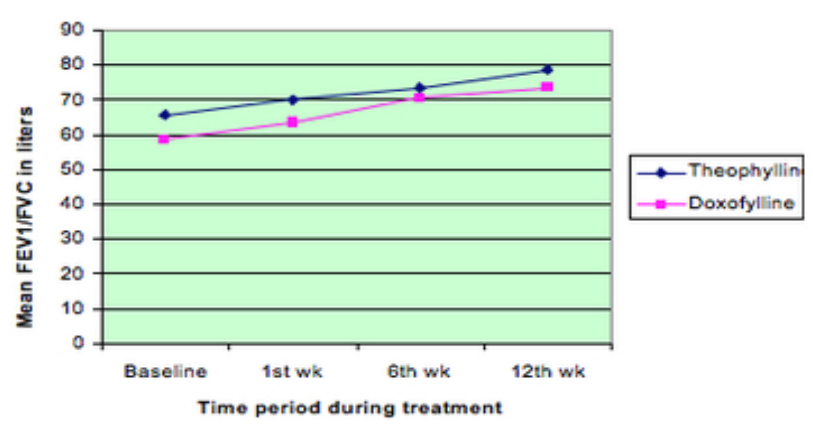

Figure 3: Spirometric changes in mean values of FEV1/FVC during the therapy with doxofylline and theophylline.

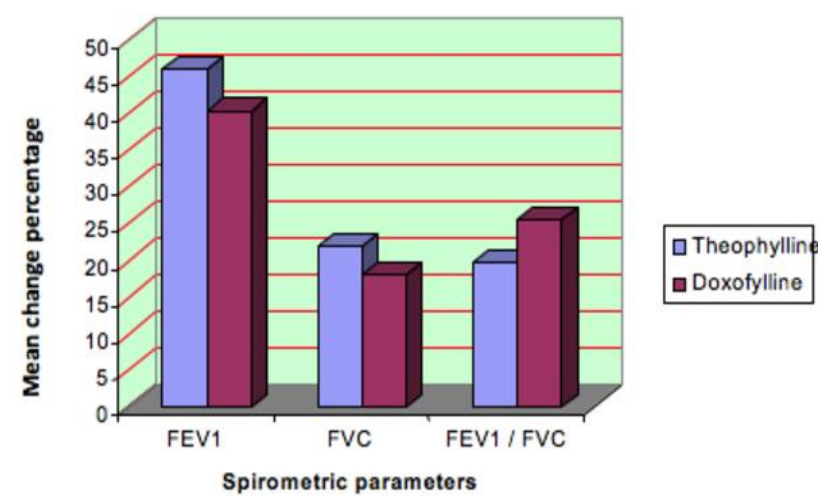

Figure 4: Spirometric changes of mean percentages in values of FEV1, FVC and FEV1/FVC during the therapy with doxofylline and theophylline.

Symptomatic improvement was observed by both the groups of patient i.e. score for cough, sputum shortness of breath, nocturnal exacerbation of symptoms, severity has come down in regard to base line with significant value $(\mathrm{P}<0.05)$. Mean score improvement of cough and SOB (shortness of breath) in COPD patients during 12 weeks are shown in the Table 2 and Figure 5. Nocturnal severity of symptoms score (NSS) also showed improvement by $33 \%$ and $30 \%$ in theophylline and doxofylline groups respectively as shown in Table 3 and Figure 5.

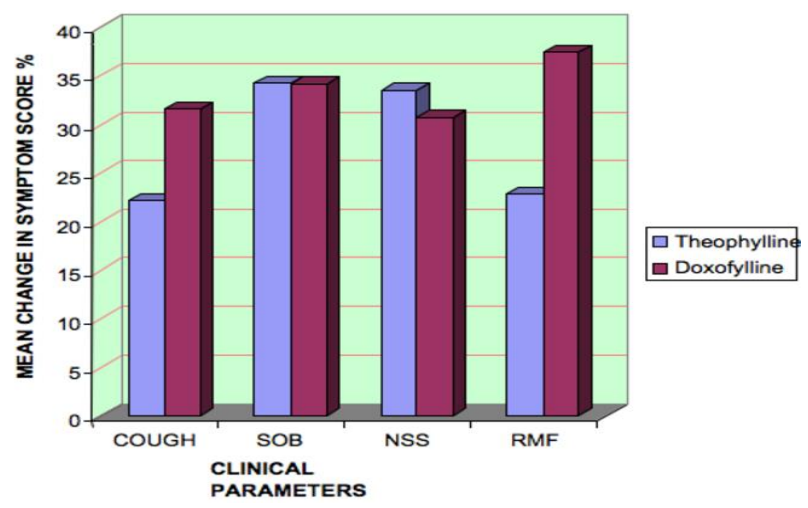

Figure 5: Spirometric changes of mean percentages in values of nocturnal severity of symptoms score (NSS) and risk medication frequency (RMF) use, during the therapy with doxofylline and theophylline. 
Table 2: Mean score improvement of cough and SOB (shortness of breath) during the therapy with doxofylline and theophylline.

\begin{tabular}{|lllllll|}
\hline Group & $\begin{array}{l}\text { COUGH } \\
\text { Mean value } \\
\text { before Rx }\end{array}$ & $\begin{array}{l}\text { Mean value } \\
\text { After Rx }\end{array}$ & $\begin{array}{l}\text { Mean } \\
\text { change } \%\end{array}$ & $\begin{array}{l}\text { Mean value } \\
\text { before Rx }\end{array}$ & $\begin{array}{l}\text { Mean value } \\
\text { after Rx }\end{array}$ & $\begin{array}{l}\text { Mean } \\
\text { change \% }\end{array}$ \\
\hline I Theophylline N=18 & 1.888 & 1.470 & 22.13 & 1.944 & 1.277 & 34.31 \\
\hline II Doxofylline N=20 & 2.05 & 1.4 & 31.7 & 1.9 & 1.25 & 34.21 \\
\hline
\end{tabular}

Table 3: Mean score improvements of nocturnal severity of symptoms score (NSS) and risk medication frequency (RMF) in COPD during therapy with doxofylline and theophylline.

\begin{tabular}{|c|c|c|c|c|c|c|}
\hline Group & NSS & & & RMF & & \\
\hline & $\begin{array}{l}\text { Mean value } \\
\text { before Rx }\end{array}$ & $\begin{array}{l}\text { Mean value } \\
\text { after Rx }\end{array}$ & $\begin{array}{l}\text { Mean } \\
\text { change \% }\end{array}$ & $\begin{array}{l}\text { Mean value } \\
\text { before Rx }\end{array}$ & $\begin{array}{l}\text { Mean value } \\
\text { after Rx }\end{array}$ & $\begin{array}{l}\text { Mean } \\
\text { change \% }\end{array}$ \\
\hline I Theophylline $(\mathrm{N}=18)$ & 2 & 1.133 & 33.5 & 1.944 & 1.5 & 22.83 \\
\hline II Doxofylline $(\mathrm{N}=20)$ & 1.95 & 1.35 & 30.76 & 1.95 & 1.22 & 37.43 \\
\hline
\end{tabular}

Frequency of risk medication also decreased by mean change of $22.83 \%$ in theophylline group and $37.43 \%$ in doxofylline group in the period of 12 weeks with regard to baseline $(\mathrm{P}<0.05)$ as shown in Table 3 and Figure 5. Both the drugs were well tolerated without any major adverse event by most of the patients. Overall, the adverse events were found to be more in the theophylline group when compared to doxophylline group.

\section{Table 4: Adverse events experienced during the therapy with doxofylline and theophylline.}

\begin{tabular}{|l|lll|}
\hline $\begin{array}{l}\text { Adverse } \\
\text { events }\end{array}$ & \multicolumn{2}{c}{ Theophylline } & Doxofylline \\
\hline \multirow{2}{*}{ GIT } & $\begin{array}{l}\text { Epigastric } \\
\text { distress }\end{array}$ & 6 & 3 \\
\cline { 2 - 4 } & Nausea & 6 & 2 \\
\hline CNS & Headache & 2 & 1 \\
\cline { 2 - 4 } & Digginess & 2 & 1 \\
\hline $\begin{array}{l}\text { Sleep } \\
\text { disorder }\end{array}$ & Insomnia & 2 & 0 \\
\hline CVS & Palpitation & 2 & 0 \\
\cline { 2 - 4 } & $\begin{array}{l}\text { Typical } \\
\text { chest pain }\end{array}$ & 0 & 0 \\
\hline $\begin{array}{l}\text { Drop } \\
\text { outs }\end{array}$ & & 2 & \\
\hline
\end{tabular}

Adverse events were observed in $55.5 \%$ of patients in theophylline group and in $30 \%$ of patients in doxofylline group. More adverse effects were seen in Group-I which is treated with theophylline as shown in the following Table 4. The most common side effect in both the groups was epigastric distress and nausea. Cardiovascular side effects including palpitations were reported from patients treated with theophylline only. The adverse drug reactions were mild and required only symptomatic treatment in a few cases. According to the Naranjo ADR probability scale, the adverse events were found to be probable in 8 cases $($ Score $=5-8)$, possible $($ Score $=1-4)$ in 17 cases and doubtful $($ Score $=0)$ in other cases.

\section{DISCUSSION}

COPD is a potentially fatal slowly progressive respiratory disease. A COPD diagnosis is confirmed by a simple test called spirometry. Drug treatment includes bronchodilators and corticosteroids or both. Bronchodilators include inhaled beta-agonists and anticholinergics and methylxanthines. Doxofylline (7-(1, 3-dioxalan-2-ylmethyl) theophylline) is a novel xanthine bronchodilator which differs from theophylline in that it contains a dioxalane group in position 7 and has greatly decreased affinity towards adenosine A1 and A2 receptors which explain its better safety profile. Theophylline has an antagonistic action on the adenosine $\mathrm{A} 1, \mathrm{~A} 2 \mathrm{a}$ and $\mathrm{A} 2 \mathrm{~b}$ receptors, which is responsible for its cardiac and central nervous system stimulatory side effects. Doxofylline has been reported to have less affinity for the adenosine receptor and it has been claimed to have a better safety profile. It has been claimed to have a decreased affinity towards the adenosine $\mathrm{A} 1$ and $\mathrm{A} 2$ receptors.

In our study, both doxofylline and theophylline significantly improved spirometric values and there was significant improvement in symptoms - cough, shortness of breath and nocturnal severity of symptoms. There was a significant reduction in the use of at rescue medication during the treatment with both the drugs. The results in the patients showed that the baseline spirometric variables were similar and not statistically significant in the study groups. Active treatments resulted in improvements in the spirometric variables, which were sustained throughout the periods of the active treatment. The improvement in FEV1 was statistically significant as compared to the value at the baseline. The improvement was statistically significant at every visit as compared to 
the baseline. The percent increase in the mean FEV1 as compared to the baseline has been shown. A similar difference was observed in the FEV1/FVC ratio.

Cough score improved by $22.13 \%$ in theophylline group and by $31.7 \%$ in doxofylline group. Shortness of breath score improved by $34 \%$ (both in) and $34 \%$ in theophylline and doxofylline groups respectively. Nocturnal severity of symptoms score also showed improvement by $33 \%$ and $30 \%$ in theophylline and doxofylline groups respectively. Frequency of use of rescue medication also decreased by means change in score by $22 \%$ in theophylline group and $37 \%$ in doxofylline group. The mean FEV1 improved by 0.62 liters $(45 \%)$ in theophylline group and by 0.561 liters $(40.2 \%)$ in doxofylline group at the end of treatment $(\mathrm{P}<0.01)$. At the end point mean FVC value improved by 0.449 liters $(21.87 \%)$ in theophylline group and by 0.425 liters $(17.9 \%)$ in doxofylline group, in comparison with baseline values $(\mathrm{P}<0.01)$. The mean $\mathrm{FEV} 1 / \mathrm{FVC} \%$ ratio also improved by $19.69 \%$ in theophylline group and by $25.32 \%$ in doxofylline group, compared with baseline $(\mathrm{P}<0.01)$. The main factor limiting the use of theophylline was in fact is high incidence of side effects especially gastric distress and central nervous stimulation.

Most common side effects in our study was gastric epigastric distress $(33 \%)$ in theophylline group and $15 \%$ in doxofylline group. In this study doxofylline had a lesser number of unwanted side effects, lesser number of patients with unwanted effects, and lesser number of severe unwanted side effects as compared to theophylline.

These results are consistent with the study of Santra CK at Burdwan Medical College and Midnapore Medical College in West Bengal done as an open randomized multicentric trial. ${ }^{9}$ In that study, both drugs significantly increased spirometric parameter (doxofylline $\mathrm{p}<0.01$ and theophylline $\mathrm{p}<0.04)$ and significantly reduced salbutamol consumption ( $<<0.001$ for both drugs). Doxofylline was better tolerated than theophylline considering either the number of unwanted side-effects: (Doxofylline 8 and theophylline 25) or number of dropout side-effects (doxofylline 5 and theophylline 10). Melillo $G$ et al in 1989 have studied doxofylline and theophylline. ${ }^{10}$ Both drugs significantly increased spirometric parameters ( $\mathrm{p}$ less than 0.001 for all tests) and significantly reduced salbutamol consumption ( $p$ less than 0.001 for both drugs). Doxofylline was better tolerated than theophylline considering either the number of unwanted side-effects: (doxofylline 12; theophylline 37) or number of drop-outs due to side-effects (doxofylline 5; theophylline 10). From these results doxofylline seemed to be a good alternative to theophylline in the treatment of reversible chronic airway obstruction in view of its better safety profile. Goldstein MF et al, did the comparative study was done in three hundred forty-six patients who were randomly assigned to a 12 -week oral treatment with either doxofylline 400 $\mathrm{mg}$ tid (high dose), doxofylline $200 \mathrm{mg}$ tid (low dose), theophylline $250 \mathrm{mg}$ tid (active control) or placebo. ${ }^{11}$ Changes in FEV1 exhibited statistically significant differences between doxofylline $400 \mathrm{mg}$ tid and placebo and between theophylline and placebo. Significantly more patients had to interrupt treatment because of adverse events under theophylline than under doxofylline $400 \mathrm{mg}$ tid $(\mathrm{p}=0.001)$.

One of the major limitations of theophylline is its nonselectivity for the phosphodiasterase enzyme. This was not solved by doxofylline as well, as there is no evidence that it was a selective PDE IV inhibitor. Theophylline has an antagonistic action on the adenosine $\mathrm{A} 1, \mathrm{~A} 2 \mathrm{a}$ and $\mathrm{A} 2 \mathrm{~b}$ receptors, which is responsible for its cardiac and central nervous system stimulatory side effects. Doxofylline has been reported to have less affinity for the adenosine receptor and it has been claimed to have a better safety profile. It has been claimed to have a decreased affinity towards the adenosine A1 and A2 receptors. From these results, doxofylline seemed to be a good alternative to theophylline in the treatment of chronic obstructive pulmonary disease.

\section{CONCLUSION}

This study provides evidence that doxofylline is an effective treatment for relieving airway obstruction and displays a better safety profile with respect to theophylline with a favourable risk-to-benefit ratio.

\section{ACKNOWLEDGEMENTS}

The authors thank Osmania medical college, Hyderabad, India for providing the facilities to carry out the study. We gratefully acknowledge the cooperation and support given by the technical staff and patients, who made this work possible.

Funding: No funding sources Conflict of interest: None declared

Ethical approval: The study was approved by the Institutional Ethics Committee

\section{REFERENCES}

1. Gupta D, Agarwal R, Aggarwal AN. Guidelines for diagnosis and management of chronic obstructive pulmonary disease: Joint ICS/NCCP (I) recommendations. Lung India. 2013;30(3):228-67.

2. World Health Organisation-Burden of COPD. [Internet]. 2015. Available from: http://www.who.int/respiratory/copd/burden/en/

3. Salvi S, Agarwal A. India needs a national COPD prevention and Control program. J Asso Physicians India. 2012;60:5-7.

4. Essayan DM. Cyclic nucleotide phosphodiesterases. J Allergy Clin Immunol. 2001;108(5):671-80. 
5. Deree J, Martins JO, Melbostad H, Loomis WH, Coimbra R. Insights into the Regulation of TNF- $\alpha$ Production in Human Mononuclear Cells: The Effects of Non-Specific Phosphodiesterase Inhibition. Clinics (Sao Paulo). 2008;63(3):321-8.

6. Marques LJ, Zheng L, Poulakis N, Guzman J, Costabel U. Pentoxifylline inhibits TNF-alpha production from human alveolar macrophages. Am J Respir Crit Care Med. 1999;159(2):508-11.

7. Peters-Golden M, Canetti C, Mancuso P, Coffey MJ. Leukotrienes: underappreciated mediators of innate immune responses. J Immunol. 2005;174(2):589-94.

8. Daly JW, Jacobson KA, Ukena D. Adenosine receptors: development of selective agonists and antagonists. Prog Clin Biol Res. 1987;230(1):41-63.

9. Santra CK. Treatment of moderate chronic obstructive pulmonary disease (stable) with doxofylline compared with slow release theophylline--a multicentre trial. J Indian Med Assoc. 2008;106(12):791-4.
10. Melillo G, Balzano G, Jodice F, De Felice A, Campisi V, Capone M. Treatment of reversible chronic airways obstruction with doxofylline compared with slow-release theophylline: a doubleblind, randomized, multicentre trial. Int $\mathrm{J}$ Clin Pharmacol Res. 1989;9:397-405.

11. Goldstein MF, Chervinsky P. Efficacy and safety of doxofylline compared to theophylline in chronic reversible asthma - a double-blind randomised placebo-controlled multicentre clinical trial. Med Sci Monit. 2002;8:297-304.

Cite this article as: Nagawaram PR, Kanchanpally V. Comparative study of theophylline and doxofylline in the treatment of stable chronic obstructive pulmonary diasease. Int J Basic Clin Pharmacol 2016;5:251-6. 